\title{
TEORIA DA CULTURA NA PERSPECTIVA CRIADA PELO ENSAIO “O FUTURO DE UMA ILUSÃO” DE FREUD
}

\author{
Paulo Costa Lima*
}

\begin{abstract}
Neste artigo buscamos reconstruir os indícios de uma certa teoria da cultura presentes no discurso de Freud a partir das perspectivas criadas pelo ensaio O futuro de uma Ilusão. Registramos um curioso paralelo entre o discurso de Freud e o de John Lennon. Acompanhamos, assim, as marcas da "empreitada científica" por ele empreendida e as relações múltiplas que vão sendo estabelecidas com a cultura, especialmente a partir da análise das ideias religiosas e de sua possível origem no desamparo infantil, no desamparo humano. Discutimos ainda a natureza desse campo que toma a cultura como ensejo para análises e interpretações, a noção de "libideme" como equivalente gozosa da episteme epocal proposta por Foucault, e o horizonte de transição de uma cultura orientada pelo recalque para uma cultura orientada pela perversão - tudo isso incidindo diretamente sobre a vida e sobre a arte e produzindo questỗes urgentes e aparentemente não resolvíveis.

PALAVRAS-CHAVE: Cultura e psicanálise. Hermenêutica cultural. Composição e cultura. Música e psicanálise. Religião e cultura.
\end{abstract}

Só alguém dentro de uma situação pode julgá-la, ele é a última pessoa que pode julgar.

Bertolt Brecht

\section{INTRODUÇÃO: uma revolução erótica universal}

A idéia motriz deste trabalho surge da constatação de que Freud, ao problematizar a religião - ou melhor, as idéias religiosas - faz isso pela via da cultura:

Quando já se viveu por muito tempo numa civilização específica e com frequência se tentou descobrir quais foram suas origens e ao longo de que caminho ela se desenvolveu, fica-se às vezes tentado a voltar o olhar para outra direção e indagar qual o destino que a espera e quais as transformações que está fadada a experimentar (Freud, 1974 [1927], p. 15).

Parece, dessa forma, bastante justificável proceder a um exame mais detalhado de como o pensamento sobre cultura vai permitir esse aporte analítico. Faremos isso acompanhando, no próprio texto, o desafio de estruturação do pensamento do autor, mas também avaliando as projeções de algumas

* Compositor. Doutor em Educação e em Artes. Membro da Academia Brasileira de Música, Academia de Letras e Academia de Ciências da Bahia. Professor da Escola de Música da Universidade Federal da Bahia.

Vale do Canela s/n. Cep: 40000-010. Canela - Salvador Bahia - Brasil. paulocostalima@terra.com.br questões e ideias temáticas ali configuradas até nossos dias. Cabe, também, buscar entender esse momento do discurso freudiano no conjunto da empreitada psicanalítica e mesmo atentar para a relação mais ampla entre psicanálise e modernidade.

O texto $O$ futuro de uma ilusão de Freud (1927) reúne dez capítulos e uma dinâmica toda especial de envolvimento do leitor na própria vivência das questões por ele esculpidas. Na verdade, poderia até ser lido como uma peça de metodologia da pesquisa, envolvendo introdução e descrição do contexto de onde surge o problema (no caso, os rumos da civilização e as condições de pertencimento), justificativas e fundamentação (o embate entre natureza e civilização), recorte da questão central ("em que reside o valor peculiar das ideias religiosas?”), abordagem dessa questão sob ângulos diversos ("onde reside a força interior dessas doutrinas e a que devem sua eficácia?”), definição dos termos utilizados (o que são ideias religiosas? o que é mesmo ilusão?), desenvolvimento da discussão (feito através de diálogo com um personagem antagonista fictício, a partir do capítulo 4), conclusões, consequências e reco- 
mendações finais (por exemplo, “Os homens não podem permanecer crianças para sempre [...] Podemos chamar isso de educação para a realidade”), ou então a famosa fórmula de encerramento, "Não, nossa ciência não é uma ilusão. Seria ilusão, porém, acreditar que pudéssemos conseguir em outra parte aquilo que ela não pode nos dar.” Vejamos como o próprio autor descreve sua trajetória de trabalho:

Tome minha tentativa pelo que ela é. Um psicólogo que não se ilude sobre a dificuldade de descobrir a própria orientação neste mundo, efetua um esforço para avaliar o desenvolvimento do homem, à luz da pequena porção de conhecimento que obteve através de um estudo dos processos mentais de indivíduos, durante seu desenvolvimento de crianças a adultos. Ao agir assim, impõe-se a ele a idéia de que a religião é comparável a uma neurose da infância, e é otimista bastante para imaginar que a humanidade superará essa fase neurótica, tal como muitas crianças evolvem de suas neuroses semelhantes (Freud, 1974 [1927], p. 67).

Essa descrição trata de um discurso analítico com orientação científica, onde se faz referência a um estudo que a sustenta - o estudo dos processos mentais de indivíduos -, e a uma possível correlação. Estamos no âmbito da conexão entre os processos de maturação subjetiva e os processos de modernização social, aproximados por uma mesma lógica evolucionista. O tema atravessará o século, aparecendo em formações discursivas diversas, e nos atingindo com igual intensidade, a travessia entre o âmbito do indivíduo e o grupo, a sociedade, a cultura - e vice-versa. Nos dias de hoje, no campo da psicanálise, permanece em pauta a construção de vínculos entre a clínica e os estudos culturais.

Mas não é só isso que transpira do trecho acima. Para Safatle (2009), o caminho de Freud reunirá três grandes visões de mundo (Weltanschauung) - a animista (ou regime de encantamento), a religiosa (ou ético-religiosa) e a científica (culminando com a própria psicanálise) num percurso sintético de três etapas:

Elas se organizam como correspondentes de um processo de maturação subjetiva que vai: i. em direção ao narcisismo primário com seus pro- cessos projetivos; ii. posteriormente, à experiência do desamparo com a internalização da Lei social através da constituição de uma instância moral de observação (supereu); iii. por fim, ao esboço de realização de expectativas emancipatórias (p. 360).

É preciso acentuar o papel desempenhado pela segunda etapa desse ciclo - a internalização da Lei social - porque é justamente um momento especial de coalizão entre indivíduo e cultura. A experiência da clínica trouxe para a pesquisa de Freud a convicção da importância do embate entre a dimensão pulsional e esse núcleo teológico-político (para usar a expressão de Safatle) qua instância moral de observação, para os destinos do indivíduo.

Esse viés interpretativo nos afasta da ideia de que estejamos apenas diante de um embate entre luzes e superstição (de resto, retardatário), entre método científico e obscurantismo medieval. Freud está preocupado com a permanência incisiva, em plena modernidade, desse núcleo teológico-político, em torno do qual a vida vai sendo organizada - o embate verdadeiro seria, dessa forma, entre a permanência desse núcleo e a possibilidade aventada por Freud de crítica das ilusões.

E vale a pena lembrar: Freud não reduz o campo das ilusões à religião. Mesmo de forma incipiente, observa (1974): "Não devem as suposições que determinam nossas regulamentações políticas serem chamadas também de ilusões?” (p. 47). Abre, assim, o caminho para uma série de aproximações futuras nessa direção - talvez a mais recente sendo o diálogo entre marxismo e psicanálise cultivado por Slavoj Zizek, elaborando uma costura fina entre, de um lado, conceitos como sintoma, mais-gozar, pulsão e o Real, e, de outro, fetichismo da mercadoria, mais-valia, luta de classes e base/superestrutura. Está aí um exemplo concreto de projeção de uma temática.

Essa linha de pensamento sobre a instância moral também ecoa no estudo abrangente dedicado à ideologia da estética desenvolvido por Eagleton (1993). Ele finaliza o capítulo destinado a Freud observando que "a moral tem sua origem não no superego, mas na gratidão afetuosa do bebê pelos cuidados que recebe dos mais velhos” (p. 209). 
Sendo assim, herdamos o problema político de que "a aprendizagem do amor no bebêé inseparável da reverência pela autoridade”. Como alcançar um estilo de amar mais recíproco e igualitário? $\mathrm{E}$ isso, nos diz ele, seria um dos objetivos da psicanálise, tanto quanto da política revolucionária. Essa é, sem dúvida, uma interface muito importante para uma releitura do ensaio de Freud.

Recolho, portanto, com grande interesse, uma curiosa expressão utilizada pelo psicanalista argentino-baiano Emilio Rodrigué em sua biografia de Freud. Ao comentar as cores sombrias do ensaio O mal estar na civilização (1929-1930), escrito logo após O Futuro de uma Ilusão (2012 [1927]), Rodrigué faz questão de lembrar outra época de cores mais vibrantes e sonhadoras, e traz à baila esse trecho de uma carta escrita a Jung, em 13 de janeiro de 1910: "Estou convencido de que a bandeira da psicanálise deve tremular sobre o território da vida amorosa normal”. Pois é, arremata Rodrigué (1995): "Freud, alguma vez, acreditou numa revolução erótica universal” (p. 239).

"Revolução erótica universal": a expressão é mesmo interessante. Porém, até a presente data, o resultado de sua pesquisa nas máquinas de buscas é simplesmente nulo. E, no entanto, ela exprime e reúne uma quantidade enorme de fenômenos e intuições que se estendem pelo menos do início do século passado até hoje.

De forma especial ela dialoga com o nosso imaginário cultural, com a Bahia - que, como núcleo original da identidade brasileira, foi tantas vezes associada ao lugar paradisíaco da ausência de pecado. As vicissitudes do superego, da ausência de culpa, num lugar da periferia do capitalismo incipiente. Não podemos mesmo duvidar de que, se existe qualquer coisa denominada de "revolução erótica universal”, Gregório de Mattos deve ser considerado um dos seus ativistas.

Vale frisar: acreditar numa revolução erótica universal significa estar envolvido nesse embate com os limites da moral e da tradição, os mesmos que aparecem na clínica a partir do esforço analítico. Porém, mesmo em seus últimos escritos, quando as cores são mais sombrias e prevale- ce o interesse pelo mal-estar na cultura, permanece em Freud a consciência e o ativismo com relação aos malefícios e mesmo à injustiça das limitações morais tradicionais.

A escolha de objeto do indivíduo sexualmente maduro é reduzida ao sexo oposto, a maioria das satisfações extragenitais é interditada como perversão. A exigência expressa em tais proibições, de uma vida sexual uniforme para todos, ignora as desigualdades na constituição sexual inata e adquirida dos seres humanos, priva um número considerável deles do prazer sexual e se torna, assim, a fonte de grave injustiça (Freud, 2011, p. 50).

A transformação radical durante o século XX dos costumes e da moral ligados à sexualidade é algo que nos acostumamos a considerar natural, ou seja, parte de um processo necessário de modernização e esclarecimento, conduzido em prol de uma racionalidade que nos parece tão inquestionável como a evolução dos meios de transporte ou das comunicações. Difícil reconstruir a intensidade das transformações, a dimensão dos embates, os ritmos com que aconteceram, e, sobretudo, a mobilização de esferas tão diversas, como o âmbito das relações econômicas e políticas, o mundo do trabalho, a educação, a cultura. Multifacetado que seja, tal processo teve uma contribuição decisiva da psicanálise.

Não há como negar que a década de 60 teve um papel especial nesse longo processo, e representou uma etapa diferenciada de transformação da mentalidade comum, no embalo de fenômenos culturais de impacto mundial, tal como os Beatles. Pouco se fala de um diálogo entre Lennon e Freud, e, no entanto, como mostram os dois excertos abaixo, eles parecem estar entoando um dueto bastante afinado, como se a letra da canção Imagine saísse diretamente do último capítulo do ensaio $O f u$ turo de uma ilusão.

$$
\begin{array}{r}
\text { Imagine there's no heaven / It's easy if you try } \\
\text { No hell below us / Above us only sky } \\
\text { Imagine all the people / Living for today } \\
\text { (John Lennon) } \\
\text { Isso soa mesmo grandioso! Uma humanidade } \\
\text { que renunciou a todas as ilusões } \\
\text { e assim se tornou capaz de se organizar de } \\
\text { modo tolerável na Terra! } \\
\text { (Freud, 2012, p. 122 ) }
\end{array}
$$


De forma mais direta ainda, e tomando como ponto de intensificação poética a citação do verso de Heine-Den Himmel überlassen wir, Den Engeln und den Spatzen (Deixemos o Céu aos anjos e aos pardais) - Freud nos fala dessa nova humanidade, fortalecida pelo conhecimento científico:

Que lhe deve importar a miragem de um latifúndio na Lua, de cujas colheitas jamais alguém viu coisa alguma? Na condição de pequeno lavrador honesto nesta Terra, ele saberá cuidar de sua gleba de maneira que ela o alimente. Por não colocar mais suas expectativas no além e concentrar todas as forças liberadas na vida terrena, provavelmente ele consiga que a vida se torne suportável para todos e que a cultura não oprima mais ninguém (2012, p. 121).

Ora, a utopia de Lennon não surge de nenhum veio científico, e sim de seu envolvimento com a música e com a projeção, em escala global, de suas canções, ampliando os patamares da indústria cultural a níveis inéditos. Envolve a ultrapassagem da religião, mas também da guerra, da existência de países, da existência de propriedade - ou seja, desenha um confronto direto com representações múltiplas da autoridade, e mesmo um devaneio com a abolição dessas formas tradicionais de suporte simbólico.

Lennon foi um personagem especialmente talhado pelas circunstâncias da vida a incorporar esse discurso utópico - membro da geração que cresceu durante o pós-guerra, teve uma experiência familiar atribulada, pouco contato com os pais, criado por uma tia e perdeu a mãe aos 17 anos, o que deixou tudo em suspenso. Reúne, portanto, em si, a instabilidade necessária, a hostilidade necessária, para propor esses rompimentos radicais.

Mother, you had me / but I never had you

I wanted you/ but you didn't want me

Através da canção Mother, por exemplo, e já no período pós-Beatles, ele insinua o desejo de transar com a própria mãe (Julia). Não lembro outro caso de Édipo assim quase explícito em canções. A canção sustenta um grito, um apelo, uma agonia. Há um sofrer sendo exposto, e há uma perplexidade que paira sobre tudo De onde vem essa originalidade? Freud pariu Lennon? E ele assim se torna personagem da narrativa desencadeada pela recepção do texto freudiano, inclusive $O f u$ turo de uma ilusão?

Mas talvez o traço mais distintivo da canção seja o seu investimento numa exposição deslavada da intimidade emocional-existencial de seu autorcelebridade. Como se ali estivesse acontecendo uma travessia radical para um outro ambiente.

É o mesmo herói que decide ficar nu pela paz, que devolve a medalha à Rainha porque não aceita a guerra, que embarca no sonho da realidade ampliada e que um dia se imaginou mais famoso que Jesus Cristo, tendo sido, anos depois, assassinado por um fã obcecado pela sua imagem.

Ora, os ingredientes desse caso reverberam até hoje, e até certo ponto moldam a condição cultural dos nossos dias, na medida em que o papel de celebridade, a função-celebridade, se assim pudermos falar, é avaliada em termos da quantidade de prazer ou gozo que aparenta desfrutar - as capas das revistas são o cenário mais visível desse processo-, e também na medida em que a intensidade desse prazer ou gozo está ligada à sua capacidade de flexibilizar tabus e lei.

Lennon representa, sem sombra de dúvida, um novo patamar de intensidade com relação ao experimento com a figura da celebridade como sedução de uma massa mundial de indivíduos prontos para uma identificação sem precedentes. Uma experiência com o poder assim desencadeado, que tem muitos traços semelhantes ao culto religioso. A fusão-confusão emocional entre pessoas da massa e herói (novo estágio de lucratividade) gera uma miríade de situações e a desconstrução das narrativas tradicionais que amarravam esses indivíduos a seus contextos locais.

É como se o herói ameaçasse roubar o lugar da referência simbólica (da lei) e redesenhar os caminhos de regulação do gozo. Mas, estranha circunstância: a utopia de Lennon não se dá conta da severa clivagem que a sustenta? Ou seja: o paradoxo entre o discurso de desconstrução da autoridade e a entronização absoluta feita a partir do lugar-de-fala desse novo poder mundial que é a celebridade? 
Como reagir diante de um discurso que promete a liberdade total diante das seculares barreiras entre os homens, que promete uma equanimidade radical, se esse discurso inaugura um novo patamar de sedução e isolamento, e, portanto, de uma quase total incompatibilidade entre massa e celebridade?

Voltando ao discurso de Freud. Não há como negar sua adesão permanente a um esforço de sofisticação de conceitos que consigam dar conta da experiência psicanalítica, mas há também um claro investimento em transformar mentalidades, "educar para a realidade", como registramos acima. A leitura de um trecho da parte final, capítulo IX, ilustra esse ponto:

Sem dúvida é insensato começar a tentar eliminar a religião pela força, e de um só golpe. Acima de tudo, porque isso seria irrealizável. O crente não permitirá que sua crença lhe seja arrancada, quer por argumentos, quer por proibições. E mesmo que isso acontecesse com alguns, seria crueldade. Um homem que passou dezenas de anos tomando pílulas soporíferas, evidentemente fica incapaz de dormir se lhe tiram sua pílula. Que o efeito das consolações religiosas pode ser assemelhado ao de um narcótico é fato bem ilustrado pelo que está acontecendo nos Estados Unidos [escrito durante o período da Lei Seca]. Lá estão tentando agora - claro que sob a influência de um domínio feminista -, e, em vez delas, a título de compensação, empanturram-no de devoção. Trata-se de outro experimento sobre cujo resultado não precisamos sentir-nos curiosos (Freud, 1974 [1927], p. 63).

Não espanta, dessa forma, que um analista de mais de 50 anos de prática como Emilio Rodrigué (1995, p.219), apaixonado pela obra freudiana, em torno da qual diz cultivar tanto a identificação profunda como certo distanciamento, tenha escrito: “[...] desde a primeira página, ' $\mathrm{O}$ futuro de uma ilusão' apresenta-se como um estranho panfleto". Um panfleto? E ainda por cima, estranho. Pois bem, essa não é uma expressão tão distante assim do tom daquilo que inicia o trecho citado acima: "[...] é insensato começar a eliminar a religião pela força, e de um só golpe”. O autor estaria, dessa forma, em plena campanha, discutindo estratégias.

Mas, por outro lado, há uma série de ou- tros atributos que merecem consideração. Além da coragem de colocar em discussão assuntos tão delicados, esse seria um "panfleto" capaz de prever aspectos do futuro? Ao se referir à força das "consolações religiosas" e sua imbricação com a Lei Seca, parece tocar em algo bastante atual. Não estaria prevendo o fundamentalismo religioso americano dos nossos dias, que teve em George W. Bush um dos seus mais legítimos e tenebrosos representantes? Ou seja, conseguindo farejar um traço cultural importantíssimo para uma visão interpretativa dos Estados Unidos da América? (E isso sem mencionar o feminismo).

As observações penetrantes de Freud têm uma capacidade estranha de reverberar pelos tempos a fora. No texto que escreveu logo após este, e que, de certa forma, continua seu traçado-que é $O$ mal-estar na civilização (1929-1930) -, ao tratar do papel desempenhado pela propriedade privada como anteparo para as inclinações agressivas do ser humano, uma perspectiva até então pouco visitada, ele dispara o seguinte comentário: "Não se pode senão imaginar, com preocupação, sobre o que farão os soviéticos depois que tiverem eliminado seus burgueses" (Freud, 1974 [1927], p. 137). Hoje, sabemos a resposta.

A leitura desses textos e as orientações neles contidas nos levam a concordar com a interpretação dada por Joel Birman (2011) com relação ao real objeto e conteúdo desse caminho um tanto inesperado tomado pelo pai da psicanálise a partir de Totem e Tabu:

Freud se deslocou entre dois polos, que se contrapõem em seus menores detalhes, como veremos. Com efeito, se no começo de seu percurso teórico Freud acreditou na harmonia possível entre os registros do sujeito e do social, em seguida essa harmonia foi colocada incisivamente em questão, de maneira que a problemática do desamparo do sujeito no campo social foi a marca decisiva de sua leitura da inserção do sujeito na modernidade (p. 133).

Não há como negar que, tanto em $O$ futuro de uma ilusão como em o Mal-estar na civilização, o tema do desamparo é central. Freud desenha, sim, um mapa do mal-estar na modernidade. Po- 
rém aquilo que consideramos como questão motivadora do presente artigo é que esse desenho, essa construção, se apoia em análises da cultura (ou civilização, já que o autor diz desprezar distinguir os dois conceitos). Trata-se de indagar sobre o futuro da civilização e sobre possíveis mecanismos internos de transformação. Para Rodrigué (1995):

As reflexões iniciais sobre a cultura são propositais - laicizar o tema começando onde 'Totem e Tabu' acaba. A religião, inscrita em uma antropologia cultural, torna-se acessível à investigação científica (p. 219).

Laicizar o tema para torná-lo acessível à investigação científica. Ora, essa formulação expõea estratégia do autor e soa quase comouma interpretação. Mas, qual é mesmo o papel da cultura como lastro fiador das questões que vão sendo colocadas? Qual ocampo de conhecimento que vai sendo desenhado quando acompanhamos Freud nessas suas reflexões?

A formulação de Rodrigué é de que a operação envolve inscrever a religião em "uma antropologia cultural". Acho muito interessante o artigo indefinido - "uma antropologia cultural" - porque denota a consciência da pluralidade, ou melhor, de que não havia um campo pré-existente pronto para receber tais reflexões, seria preciso moldar algo. Obviamente, não existe, naquele momento, nenhuma antropologia capaz de simplesmente absorver os conceitos psicanalíticos trazidos da clínica do indivíduo. Portanto, trata-se de inscrever um objeto um tanto improvável (a religião) em um campo que, a rigor, ainda não existe, para poder tratá-la com as ferramentas da ciência. É uma operação complicada.

Ao final do texto de O mal-estar na civiliza ção a consciência sobre o desafio cognitivo envolvido na tarefa de colocar a cultura como objeto de interesse analítico aparece de corpo inteiro:

Não posso dizer que uma tentativa dessas, de transferência da psicanálise para a comunidade cultural, não teria sentido ou estaria condenada à esterilidade. Mas teríamos de ser muito prudentes, e não esquecer que se trata apenas de analogias, e que não apenas com seres humanos também com conceitos é perigoso retirá-los da esfera em que surgiram e evoluíram. O diagnós- tico das neuroses da comunidade também encontra uma dificuldade especial. Na neurose individual nos serve de referência imediata o contraste que distingue o enfermo de seu ambiente, tido como 'normal'. Tal pano de fundo não existe para um grupo igualmente afetado, teria que ser arranjado de outra forma. E no que diz respeito à aplicação terapêutica da compreensão, de que adiantaria a mais pertinente análise da neurose social, se ninguém possui a autoridade para impor ao grupo a terapia? Apesar de todas essas dificuldades, pode-se esperar que um dia alguém ouse empreender semelhante patologia das comunidades culturais (Freud, 2011, p. 92).

Vemos, portanto, que a consciência de estar abrindo um novo campo de estudos, mesmo que através de analogias, aparece de forma bastante provocativa nesse trecho.

A interação entre a clínica e os estudos culturais permanece como desafio e limite criativo. A empreitada interpretativa que remonta a essa trilha diversificou-se em muitos ramos teóricos que vão dos estudos culturais à própria psicanálise da cultura e da sociedade, passando pelo trabalho da Escola de Frankfurt, pelos trabalhos de psicanálise dita aplicada, em arquitetura, literatura e artes.

\section{PROBLEMATIZAÇÃO}

Tão relevante quanto a identificação do campo a ser criado é a identificação das estratégias cognitivas utilizadas para o enfrentamento daquilo que está sendo proposto. Fiel à tradição científica, Freud acredita em esculpir cuidadosamente os problemas aos quais se dedica.

Depois de apresentar, durante dois capítulos, o contexto de onde imagina que deva surgir sua problematização - notadamente, a análise dos mecanismos de atração e repulsão entre indivíduos e civilização -, Freud prepara, no final do segundo capítulo, uma elegante transição para o viés específico que pretende abordar.

Após reconhecer e listar as situações de repressão e de renúncia instintual que advêm do estado de civilização, e que, inclusive, dão origem a um processo bastante complexo de internalização das normas e preceitos morais, denominado de superego, Freud (1974 [1927], p. 24) reconhece ou- 
tras vantagens "sob forma de ideais e criações artísticas, isto é, satisfações que podem ser derivadas dessas fontes".

É também nesse ponto que aborda a satisfação narcísica proporcionada pelos ideais que determinam a unidade cultural, o "orgulho pelo que já foi alcançado com êxito”, mas também "a discórdia e inimizade entre unidades culturais diferentes". Uma observação cheia de nuances, especialmente nesse período entre guerras - mas que também poderia ser deslocada para o campo das relações interculturais mais amplas. Daí, passa à consideração da arte:

Como já descobrimos há muito tempo, e, por esse motivo, ela serve, como nenhuma outra coisa, para reconciliar o homem com os sacrifícios que tem de fazer em benefício da civilização (p. 25).

Dito isso, sente-se pronto para realizar a transição efetiva:

Nenhuma menção se fez ainda do que talvez constitua o item mais importante do inventário psíquico de uma civilização, item este que consiste, no sentido mais amplo, em suas ideias religiosas, ou, em outras palavras (que posteriormente serão justificadas), em suas ilusões (p. 25).

"Nenhuma menção se fez ainda": o artífice tem consciência da estratégia dramática de preparação do terreno após dois capítulos de perambulações introdutórias buscando uma posição privilegiada diante da oposição que imagina. E agora, ao iniciar o terceiro capítulo, pode ser bastante objetivo ao perguntar (1974 [1927]): Em que reside o valor peculiar das idéias religiosas? (p. 26). ${ }^{1}$

Essa é a questão central, em torno da qual gira todo o texto. Sutilmente, a questão da religião é traduzida em termos de "ideias religiosas" (ou melhor, representações) — ideias e representações fazem parte do psiquismo e, particularmente, do campo que o autor fundou, a psicanálise. Como questionar que há uma contribuição a ser dada

1 "Worin liegt der besondere Wert der religiösen Vorstellungen?" Vale observar: Freud usa a palavra 'Vorstellungen' (representações) e não Ideen (ideias) tal como aparece nas traduções para o inglês e para o português. nessa perspectiva? E, assim, de forma sempre experimental, Freud vai consolidando a possibilidade de concepção de um trabalho de transferência visando a uma coletividade.

E, nesse sentido, merece atenção diferenciada a expressão "inventário psíquico de uma civilização", pois ela materializa uma descrição feita pelo próprio autor sobre a natureza da empreitada. Quais as vicissitudes desse "campo" insinuado por Freud a partir da consideração da cultura, vis-à-vis a experiência do Inconsciente?

\section{FUNDAMENTAÇÃO: Civilização versus Natureza}

O próximo passo consiste em descrever em detalhe a oposição entre civilização e natureza. Esta, reunindo forças de grande magnitude contra as quais ficaríamos indefesos, não fosse o longo processo de construção coletiva chamado de civilização - que protege o ser humano, mas dele exige uma série de regulamentos, gerando uma hostilidade significativa. Está aí, portanto, o modelo básico que irá fundamentar as análises posteriores.

Um dos mecanismos mais notáveis de reagir ao desamparo seria da ordem da projeção. Portanto, diz Freud (1974 [1927]):

... se tudo na natureza forem Seres à nossa volta, do mesmo tipo que conhecemos em nossa própria sociedade, então poderemos respirar livremente... Contra esses violentos super-homens externos, podemos aplicar os mesmos métodos que empregamos em nossa sociedade; podemos tentar conjurá-los, apazigua-los, suborná-los, e, influenciando-os assim, despojá-los de uma parte de seu poder (p. 28).

Uma vez identificado esse mecanismo básico - presente nas ideias de que "tudo que acontece nesse mundo constitui expressão das intenções de uma inteligência superior" Freud (1974 [1927]) - basta estender o raciocínio um pouco mais, afirmando que o protótipo para esse estado de coisas vem da própria infância, ou seja, da experiência pessoal de desamparo: 
Já uma vez antes, nos encontramos em semelhante estado de desamparo: como crianças de tenra idade, em relação a nossos pais... Do mesmo modo, um homem transforma as forças da natureza não simplesmente em pessoas com quem pode associar-se como com seus iguais pois isso não faria justiça à impressão esmagadora que essas forças causam nela - , mas lhe concede o caráter de um pai (p. 28).

\section{DOMÉTODO}

E, uma vez desenhada a questão e o contexto de onde surge, o ímpeto científico do autor concentra-se no próprio caminho de pesquisa, a dimensão do método - que, aliás, esteve presente desde o início, na própria formulação das questões. Falar de método em Freud significa colocar em tela a estratégia metodológica central à psicanálise, sua audição e escrutínio especiais do discurso - audição e escrutínio que também projetam a noção de transferência e sua gestão na clínica. Sem a experiência da clínica, não haveria a empreitada psicanalítica na direção de outros campos de estudos. A dimensão do método, nesse ensaio, também envolve uma série de escolhas quanto ao estilo de apresentação e de argumentação - por exemplo, passa a dialogar com um suposto opositor que segue levantando senões desde o quarto capítulo até o final -, mergulha na lapidação das próprias questões apresentadas, busca definir cuidadosamente os termos utilizados.

Sobre a lapidação das questões, temos, no início do quinto capítulo, um bom exemplo (Freud, 1974 [1927], p. 37): "Qual é, então, a significação psicológica das ideias religiosas e sob que título devemos classificá-las?" Passamos do "valor peculiar" das idéias religiosas, na versão anterior, à busca da "significação psicológica", algo bem mais específico. Nesse ponto, reconhece a necessidade de classificação ou definição do que sejam essas "ideias", e comenta:

Após rejeitar uma série de formulações, nos fixaremos na que se segue. As ideias religiosas são ensinamentos e afirmações sobre fatos e condições da realidade externa (ou interna) que nos dizem algo que não descobrimos por nós mesmos e que reivindicam nossa crença (p. 37).
Também se preocupa em definir com cuidado o que seria, de fato, uma ilusão:

Uma ilusão não é a mesma coisa que um erro; não é, tampouco, necessariamente um erro. A crença de Aristóteles de que os insetos se desenvolvem do esterco [...] era um erro [...] Por outro lado, foi uma ilusão de Colombo acreditar que descobriu um novo caminho marítimo para as Índias. $\mathrm{O}$ papel desempenhado por seu desejo nesse erro é bastante claro. Pode-se descrever como ilusão a asserção feita por certos nacionalistas de que a raça indo-germânica é a única capaz de civilização, ou a crença, que só foi destruída pela psicanálise, de que as crianças são criaturas sem sexualidade (p. 37).

Portanto, o característico das ilusões é que derivam de desejos humanos. Como lembra Rodrigué (1995): "Elas carregam a insistência de uma pulsão", e ainda ecoando Freud, estariam próximas do delírio.

Com relação ao estilo de escrita e apresentação, não custa lembrar que Freud foi premiado em sua maturidade, em 1930, com o Prêmio Goethe tal o apreço pela qualidade do seu texto. E, justamente, um dos atributos mais louvados é a clareza, obtida através de estratégias de apresentação de um pensamento que vai se pensando.É uma estratégia adequada para quem teve que enfrentar o desafio de relatar embates com fenômenos postos à margem da racionalidade comum, tais como a psicopatologia cotidiana, os chistes, os sonhos e sintomas.

Trata-se, dessa forma, de uma escolha metodológica que foi amadurecida com décadas desses tipos de enfrentamento, e que consegue tornar muito flexíveis e amplas, porém sem diluir, as categorias que aqui assinalamos de problematização, fundamentação e métodos.

Outro atributo metodológico extremamente importante: a ironia. Ao comentar os resultados da empreitada espírita dirá:

Invocaram os espíritos dos maiores homens e dos mais eminentes pensadores, mas todos os pronunciamentos e informações que deles receberam foram tão tolos e tão deploravelmente sem sentido que neles nada se pode encontrar de crível, exceto a capacidade dos espíritos em se adaptarem ao círculo de pessoas que os conjuraram (Freud, 1974 [1927], p. 40). 
Não sei se existe, mas deveria existir, um estudo em profundidade sobre o uso da ironia em Freud. No caso, creio que o efeito retórico permite angariar do leitor a simpatia dedicada a Davi em luta contra uma espécie de Golias, a tradição do pensamento religioso. Diversos outros artifícios retóricos compõem uma metodologia que visa à identificação do leitor com uma voz potencialmente dissonante. A técnica do pensamento que se pensa, também tem essa dimensão - evoca uma voz da área médica, do bom senso, e da razão.

Vale a pena, também, exemplificar o caminho metodológico do escrutínio crítico dos discursos. Ao indagar sobre os fundamentos das crenças religiosas, Freud (1974/1927) registra três respostas, que, a seu ver, pouco se harmonizam entre si:

Em primeiro lugar, os ensinamentos merecem
ser acreditados porque já o eram por nossos pri-
mitivos antepassados; em segundo lugar, possuí-
mos provas que nos foram transmitidas desde
esses mesmos tempos primevos; em terceiro, é
totalmente proibido levantar a questão de sua
autenticidade. Em épocas anteriores, uma tal
presunção era punida com os mais severos casti-
gos, e ainda hoje a sociedade olha com desconfi-
ança para qualquer tentativa de levantar nova-
mente a questão (p. 38).

Logo adiante, em O Mal-estar na Civilização, a atenção analítica e desconstrutiva acaba por se concentrar no enunciado moral de origem cristã: "Amarás ao próximo como a ti mesmo" (Freud, 2011 [1929/1974]). Ele assinala o conflito entre a pulsão e sua expressão nos laços sociais. Acaba apontando o lado coercitivo do enunciado - que impede a determinação do objeto, uma vez que todos deverão ser merecedores de amor. Isso permite perguntar pelas consequências de retirar o anteparo mais tradicional da hostilidade humana, o depositário principal das nossas pulsões agressivas, o inimigo, o rival. Permite também entender o papel da culpa como mecanismo de adaptação civilizatória às novas exigências de renúncia instintual. Novamente o que aparece é o núcleo teológico-político, a moral como recusa da morte de Deus, como apagamento do assassinato do pai primevo, sendo essa, segundo Safatle (2009, p. 367) a maneira disponível a Freud de dizer que, nas relações sociais atuais, os sujeitos agem a partir de encarnações imaginárias de representações fantasmáticas de autoridade e soberania.

Ao comentar a diferença do texto de 1927, com relação a Totem e Tabu, Freud (1974 [1927]) lembra que não havia sido sua intenção, no primeiro texto, explicar a origem da religião, mas apenas do totemismo:

Poderá você, segundo qualquer dos pontos de vista que lhe são conhecidos, explicar o fato de que a primeira forma pela qual a divindade protetora se revelou aos homens teve de ser a de um animal, que tenha havido uma proibição contra matar e comer esse animal, e que, não obstante, o costume solene tenha sido matá-lo e comê-lo comunalmente uma vez por ano? É exatamente isso que acontece no totemismo [...]

[...] Aceite você ou não as conclusões de Totem e Tabu, espero que admita que uma série de fatos notáveis e desvinculados são nele reunidos num todo coerente (p. 35).

Além de deveras interessante, o trecho revela o cientista diante do seu método - a construção de um todo coerente que reúne (e explica) fatos notáveis e desvinculados. A mesma observação valeria para a construção de um modelo de desvendamento das neuroses, por exemplo. No caso do estudo das ilusões, acaba descobrindo sua importância para o processo civilizatório.

Aí está o núcleo daquilo que estamos focalizando: a empreitada freudiana de imaginar um "todo coerente" que seja capaz de reunir e explicar a incidência das pulsões sobre o laço social. Ora, os dois polos apontados por Birman (2000), comentados acima, também equivalem a duas posições distintas nesse contexto:

Assim, na primeira versão freudiana sobre essa problemática, enunciou-se a hipótese de que a psicanálise poderia oferecer uma resposta resolutiva ao mal-estar na civilização, enquanto na segunda versão esta resposta cortante e absoluta foi questionada (p. 139).

\section{Já em O mal-estar na civilização:}

Em 1929, no entanto, Freud não acreditava mais nisso. A relação conflitual entre a pulsão e a civi- 
lização seria de ordem estrutural, isto é, o conflito jamais seria ultrapassado... Em contrapartida, enunciar a irredutibilidade do desamparo implica em reconhecer que o sujeito deve fazer um trabalho infinito de gestão daquela, justamente porque o desamparo originário da subjetividade seria incurável (p. 139).

Talvez, então, não haja um todo coerente, com seu poder reconfortante para a humanidade. Talvez tudo dependa justamente dessa impossibilidade de totalizar as coisas, dependa de um resto que permanece excluído. Como tantas vezes acontece nos processos de investigação, a dimensão do método acaba incidindo sobre o problema (que inicialmente o requisitara), ressignificando-o.

\section{EPISTEME E LIBIDEME}

Ciência e religião na modernidade. Parece incrível que tantos séculos tenham passado antes que uma abordagem do inconsciente fosse possível. Séculos dedicados ao desmonte gradual daquilo que passou a ser denominado de episteme da similitude - sustentada por um universo repleto de relações de semelhança - e montagem, em paralelo, da invenção e implementação da episteme ordenadora. Essa última, de índole racionalista, passa a encarar as relações de semelhança não mais como verdadeiras, e sim como uma ocasião para o erro, como argumenta Foucault (1999):

De agora em diante, cada semelhança terá de ser submetida a uma prova de comparação, ou seja, não será aceita até que sua identidade e a série de gradações de diferença onde se insere tenham sido descobertas através de medições feitas a partir de uma unidade comum (p. 35).

Se entendermos como plausível e como rica em possibilidades interpretativas a noção de episteme epocal projetada pelo trabalho de Foucault, por que não deveríamos estender essa lógica na direção do estético-libidinal? A própria clínica revela que, ao longo do último século, a prevalência dos sintomas se alterou consideravelmente. E como denominaríamos essa sazonalidade daquilo que nos atrai? Talvez devêssemos nomeála de libideme, mantendo a proximidade fonética com a ideia de Foucault.

Em O Futuro de uma Ilusão, Freud ainda acalenta a possibilidade de que a religião seja comparável a uma neurose da infância, sendo possível imaginar "que a humanidade superará essa fase neurótica”. Dois ou três anos depois, o discurso sofre uma modulação considerável, no mesmo momento retórico de encerramento do texto (Freud, 2011):

A meu ver, a questão decisiva para a espécie humana é saber se, e em que medida, a sua evolução cultural poderá controlar as perturbações trazidas à vida em comum pelos instintos humanos de agressão e autodestruição. Precisamente quanto a isso a época de hoje merecerá talvez um interesse especial (p. 93).

Ao invés da crença na força da ciência, esse registro trata de uma vinculação orgânica entre "desenvolvimento cultural" e "instinto humano de agressão e autodestruição”. A análise da cultura desemboca na questão não resolvida, e talvez não resolvível, da agressão e da autodestrutividade.

Ao confrontar a religião, através da ciência, Freud depara com a análise da cultura vis à vis a experiência do inconsciente - as idéias religiosas como instância simbólica de grande importância, reguladora de uma série de fluxos, inclusive da hostilidade e da culpa. Essa última como uma defesa imprescindível diante da ameaça perene da hostilidade e desagregação. Ao fazer isso, acaba caracterizando perspectivas que vão além daquilo que poderia ser abarcado peloâmbito da episteme ordenadora daidade moderna. O que surge em seu lugar?

\section{UMA NOVA ECONOMIA PSÍQUICA}

Ora, o estudo das ilusões é também o estudo do desamparo humano, e este, o vínculo de amor e ódio, docilidade e rebeldia que forja o superego-com implicações importantes para uma possível teoria da cultura a partir de Freud. Aquele que nos parece ter avançado de forma mais convincente no traçado das inúmeras linhas de força 
que compõem a atualidade foi Charles Melman (2003), ao falar de uma nova economia psíquica, tanto no nível do indivíduo como no do coletivo.

Ele nos fala da mutação de uma economia organizada pelo recalque para uma economia organizada pela exibição do gozo. O recalque é organizado pela queda, pelo desaparecimento ou eclipse de um objeto originário, permanecendo um fundo de ausência, que os psicanalistas denominam de castração. Nesse tipo de economia, o valor dos objetos passa pela capacidade de representação daquilo que está ausente, na esfera do desejo, e, em todos os campos (da saúde à cultura), por uma ligação e uma harmonia com algum Ideal, seja a normalidade como referência ou mesmo o estilo, e quase sempre concatenações dessas figuras de referência em torno de alguma teleologia.

Já numa economia centrada na exibição do gozo, e, portanto, na perversão, o acento recairá sobre a captura do objeto, sobre a recusa em abandoná-lo. É, dessa forma, uma economia da dependência com relação ao objeto - da adição -, não mais sua representação, e sim sua "presentação". Surge, daí, uma relação direta com o outro, aberta e de modo provocador, em torno e a propósito do objeto (Melman, 2003):

Em outras palavras, trata-se de exibir permanentemente o que de hábito se encontra mascarado, reservado, por exemplo, no momento da efusão amorosa, e de fazer de forma a que, de cara, o interlocutor seja convidado ao gozo explícito, partilhado, desse objeto. Ora, parece que esse se tornou, nos dias de hoje, um, até mesmo o comportamento comum. Esse dispositivo participa do que alimenta a economia de mercado, quer dizer, a constituição de comunidades que se agrupam em torno do mesmo objeto explícito de satisfação (p. 52).

A nova reciprocidade entre sujeitos e objetos. Os objetos não valem mais pelo que representam, por aquilo de que são representantes, mas simplesmente pelo que são. Se a utilidade desaparece, tendem a ser descartados - isso vale especialmente para pessoas (2003, p. 40): "a validade da presença de cada um no mundo se encontra discutida, discutível, já que ela só poderia ser verificada enquanto se é capaz de altas performances", no jogo social ou na atividade econômica. E isso diante de uma economia que é capaz de oferecer objetos sempre mais fantásticos, satisfações múltiplas, objetais e narcísicas.

Os sujeitos, porém, precisam ser conformados num ambiente de vácuo de alteridade, de referência ideal (2003): "A carência das identificações simbólicas só deixa como recurso, para o sujeito, uma luta incessante para conservar e renovar insígnias cuja desvalorização e renovação são tão rápidas quanto as evoluções da moda" (p. 41). E, nas tantas vezes em que o sujeito não é reconhecido, até por que não se instalou, sobrevém a violência como caminho inevitável. A tal violência que parece aleatória e despropositada.

Se o laço social e cultural surge no âmbito da relação simbólica com o Outro, o que dizer de uma época cuja tendência dominante depende justamente de mecanismos de denegação dessa instância como diferença? Na visão de Eagleton (1998):

[...] esbarramos com um sujeito pós-moderno, cuja 'liberdade' consiste num tipo de arremedo do fato de que já não existem mais alicerces alguns, que portanto está livre para transitar, seja com preocupação ou êxtase, por um universo por si só arbitrário, contingente, aleatório. O mundo, por assim dizer, fundamenta esse sujeito na sua própria ausência de fundamento [...] (p. 49).

Ora, essa operação - fundamentar o sujeito em sua própria ausência de fundamento - abre o caminho para algumas construções interpretativas, buscando atualizar a pergunta de Freud sobre o "inventário psíquico" das ilusões de uma cultura. Talvez um dos aspectos mais visíveis desse caminho seja a presença simultânea de traços aparentemente opostos e conflitantes, ou seja, clivagens. Na verdade, a falta radical de suporte simbólico altera, de forma significativa, a canalização de hostilidade, polarizando também, de maneira radical, campos de defesa dessa nova ordem e da ordem simbólica ameaçada. Isso significa a intensificação do embate entre liberalismos e fundamentalismos de ordens diversas - um jogo que acaba escondendo o lugar real do conflito. Esse, portanto, o traçado abrangente das ilusões na atualidade. 


\section{CULTURA E PÓS-MODERNISMO}

No jogo perverso de recusa da perda do objeto, será preciso negar a diferença e apresentar outra versão da função simbólica paterna. O interdito do recalque, atribuído ao pai, o torna o centro da autoridade e da proibição. Mas, a rigor, "o pai de modo algum é aquele que interdita o desejo, muito pelo contrário [...] ele é aquele que torna possível o acesso ao desejo" (Melman, 2003, p. 76). Essa interpretação unilateral ocorre com frequência em vários discursos da atualidade. Porém, contrapondo-se ao bordão anarquista "se Deus não existe, tudo é permitido", Lacan pondera: "se Deus não existe, nada é permitido".

No jogo cultural, o ocaso da instância que interdita afasta o agente de criação da sua relação de fricção com as fronteiras, retira o lastro de profundidade sobre o qual a crítica da representação, espinha dorsal do modernismo, se estabelece. A relação direta com os objetos envolve competitividade, mas não necessariamente um investimento crítico. Sendo assim, a insurgência contra os contornos formais do modernismo representará, dessa forma, uma tendência ou perspectiva de relativização da relação com o Outro. Para Eagleton (1996, p. 269), o traço do paradoxo é inerente à condição pós-moderna: "A maior parte da cultura pós-moderna é ao mesmo tempo radical e conservadora, iconoclasta e cooptada”.

Ou ainda (2011):

A cultura pós-modernista produziu, em sua breve existência, um conjunto de obras ricas, ousadas e divertidas em todos os campos da arte... Ela também gerou um excesso de material kitsch execrável. Derrubou bom número de certezas complacentes, escancarou totalidades paranóicas, contaminou purezas protegidas com desvelo, distorceu normas opressoras e abalou bases de aparência frágil... Abateu a austeridade intimidadora do apogeu do modernismo com seu espírito brincalhão, parodista e populista e assim, arremedando a forma de mercadoria, conseguiu reforçar os rigores ainda mais mutiladores gerados pelo mercado. Desatrelou o poder do local, do regional e do idiossincrático, e ajudou a homogeneizá-los em todo o globo (p. 35).
Slavoj Zizek ocupa a cena como um dos principais líderes da chamada psicanálise cultural - na esteira do marxismo psicanalítico de um Althusser, por exemplo. Uma das ideias centrais: a cultura em sua inteireza deveria ser considerada como uma 'formação de compromisso' (a denominação freudiana para a situação onde desejos inconscientes são amalgamados a representações conscientes), na verdade o resultado sintomático de um conflito. Cabe, dessa forma, como estratégia política progressiva, apenas um caminho - a desmistificação (Dean, 2002, p. 29), em oposição à veneração acrítica ou ao consumismo deslavado.

\section{FETICHE E PÓS-COLONIALISMO CULTURAL}

Obviamente, todo esse quadro pode ser transposto para a questão cultural da relação entre centro e periferias do mundo - onde se aninha a discussão da diversidade cultural e mesmo a questão cultural brasileira. Isso porque uma suposta cultura de perversão não aconteceria da mesma forma na mainstream e nos subúrbios do sistema global.

E eis que encontramos em Homi Bhabha (1994) a ideia de que esse complexo de relações poderia ser entendido melhor a partir da própria noção freudiana de fetiche. Aqui não interessa o conceito de cultura como totalidade de conteúdos canônicos. Estamos tratando da relação entre colonizados e colonizadores, circulando em contextos onde prevaleceu, durante muito tempo (e ainda prevalece), o mito da supremacia absoluta de raças (e culturas) colonizadoras.

Desse modo, o fetiche representa o jogo simultâneo e híbrido entre uma afirmação de plenitude e a ansiedade gerada pela sua falta, pela ausência, pela diferença - com relação ao discurso colonial. Entre outras coisas, o fetiche leva ao estereótipo [...] Que se multiplica para se defender da diversidade e da alteridade. A identidade, portanto, vai sendo construída nas fissuras desse mecanismo.

A teoria crítica de Bhabha não procura substituir meramente a força de um discurso hegemônico por outro marginalizado, mas, sim, instaurar um 
processo onde a autoridade e as certezas aparentes do discurso hegemônico são subvertidas, questionadas e desestabilizadas para produzir um terceiro campo, um novo discurso híbrido e libertário.

Uma possível síntese: Qual a relação entre Freud e cultura? Ora, a questão aponta na direção do núcleo político-teológico que também é estético-libidinal e certamente cognitivo, em suma, o superego, o Outro. Há um superego na coletividade, na cultura, diz Freud - e, assim como a instância individual, ele exige coisas, media identificações, regula a agressividade através da culpa -, a culpa de ser colonizado, por exemplo, um mecanismo ancestral de dominação. Presume-se que funcione, de certa forma, na cultura do recalcamento, e, de outra, na cultura da perversão. Também estaria envolvido nos meandros do grau de 'renúncia instintual' de cada coletividade-por exemplo, a alemã versus a afro-baiana, a construção do sublime versus a construção do escrache, em ambas. Se o modernismo representa um certo estágio, uma composição de forças culturais (inclusive superegoicas), um certo estágio de identificação, de representação da figura do herói, herói que administra crises e move a história, o herói da crítica da representação, o que dizer de sua ultrapassagem? E qual o horizonte para a figura da celebridade?

O que dizer da fricção entre colonizadores e colonizados, que também remete à fricção entre suas referências simbólicas e seus superegos culturais? Nesse sentido, seria interessante produzir um inventário das múltiplas formas desse tipo de fetiche, desse tipo de bloqueio da alteridade - e, da mesma forma, dos caminhos de libertação, das tentativas, das estratégias de falsificação desses clichês do fetiche. O herói brasileiro como macumba antifetiche. O fetiche que destrói outro (Macunaíma).

Ao apontar o laço entre Lennon e Freud -é claro que visualizo a migração dessa relação de fronteira para o Brasil. Por exemplo, Caetano e Gil, como figuras de ponta do movimento do sonho, da reinvenção do comportamento, do desbunde-mas só a partir de um Cazuza a vivência inquestionável de uma cultura de exposição do gozo. Noel, Caymmi e Luiz Gonzaga com traços inegavelmente de modernismo (heróis traduzidos remetem a causas...). Caetano e Gil e Lennon como figuras de transição, e Michael Jackson e Cazuza como figuras desse novo paradigma. É desse patamar que devemos entender a política cultural de Gil, os pontos de cultura, como experiência de explosão relativizadora? São formulações que respondem a uma certa teoria da cultura.

Outro contexto: a criação de música contemporânea na Bahia. A teoria proposta por Ernst Widmer sobre a formação de compositores, envolvendo duas leis - organicidade e relativização. Entendemos tal formulação como resultado do processo de travessia do próprio Widmer entre a cultura germânica e a baiana. A ideia de um encontro entre orquestra sinfônica e afoxé ilustra a "pororoca pacífica" - para usar uma expressão do próprio compositor - entre as duas culturas, e entre as duas leis. A pergunta metafísica esbarrando na exuberância dos orixás da Bahia. Então, no caso de Widmer, o percurso segue nessa direção, da organicidade para a relativização.

Já no caso dos seus alunos, esse modelo se inverte. Criados em imersão nas culturas da Bahia, eles enfrentam a organicidade germânica como desafio de desmontagem do fetiche colonizador, como desafio de instituir a diferença, mesmo no campo de sentidos claramente propostos por uma rede discursiva calcada sobre códigos de colonizadores. Surge, como programa de pesquisa, a identificação dessas estratégias na produção do movimento de composição na Bahia. Por exemplo, a relação curiosa entre os modos composicionais de Lindembergue Cardoso e Jamary Oliveira.

Este último, ao insistir no desenho meticuloso de sua música, constrói o confronto a partir de uma apropriação exacerbada, como se houvesse aprendido o regimento da contemporaneidade para além do que seus próprios inventores haviam imaginado. Essa atitude mimética, ou hipermimética, não vai parar por aí, ela é apenas a introdução para a desconstrução do fetiche. De posse desse metier, Jamary reinstala questões que são muito nossas - basta ouvir a obra Mesmamusica, para contextualizar aquilo que estou dizendo, atentos para 
a rítmica aditiva, a sucessão de grupos de cinco e de sete e suas relações com a Bahia, ou com o minimalismo, pouco importa, estamos em plenojogo.

Já em Lindembergue Cardoso a apropriação é de outra natureza. Não passa pela meticulosidade do detalhe, passa por uma relação com o desenho dramático - sendo a orquestração um dos seus melhores representantes. Cabe ao desenho dramático, à sua montagem em composição, a tarefa de conduzir o ouvinte por campos que são nossos, sem economia de exuberância - e com tal estratégia desmontar o ímpeto homogeneizador dos códigos da vanguarda. Como ouvintes, somos levados a reavaliar aquilo que somos a partir da paleta contemporânea. A música de Lindembergue tenta nos convencer, e consegue, que o contemporâneo é tão baiano-brasileiro como qualquer outro estilo. Não que não haja cálculo, há sim - mas ele opera como força subsidiária à mimeses do drama, da empatia. Obviamente, tudo isso se relaciona com sua herança de músico popular, sua vivência de relação direta com a roda de ouvintes.

O percurso da obra $O$ vôo do colibri é bastante revelador. Pode ser ouvida como um concerto contemporâneo para cravo e cordas (inclusive, com reminiscências do barroco), mas também como um diálogo crítico e cheio de humor entre essa cultura do "solismo" e as atmosferas comunais desenhadas ao final da obra pelos ritmos derivados do candomblé. O Barroco desembarcando na Bahia, uma segunda vez. A obra Ritual retoma a questão, só que de forma bem mais estrutural ainda.

Ao refletir sobre minha própria obra - e os exemplos aqui são diversos, Apanhe o Jegue, Ibejis, Atotô do l'homme armé, Bahia Concerto 2012 -, ao refletir sobre os diálogos entre atitudes e contextos contemporâneos e rítmica afrobaiana, percebo a importância da desmontagem desse fetiche que nos unificaria. Verifico que uma boa dose de energia criativa foi investida em processos que impedem a hegemonia, seja de um ou de outro contexto, exigindo uma conversa entre eles, muitas vezes uma conversa engraçada. Uma boa dose de energia investida na cons- trução de relações do tipo non-sequitur, cortes abruptos entre as duas cenas, processos que correm em paralelo, e ainda assim caminhos de conexão orgânica, celebrações.

\section{CODA}

Ao tentar explicitar o contorno de certa teoria da modernidade em Freud, Safatle (2009) observa que, para o próprio Freud, "a modernidade prometida pelo advento da visão de mundo científica está bloqueada enquanto modernização sociocultural”. E complementa:

Se o discurso científico traz uma visão desencantada de mundo clinicamente implementada pela psicanálise, visão na qual o campo de fenômenos não se submete mais a concepções totalizantes de mundo, isto não impede que as esferas da reprodução material da vida sejam ainda 'encantadas' devido à constituição superegoica de figuras sociais de autoridade... Isso talvez explique por que Freud não cessa de combater o discurso religioso [...] (p. 366).

Isso significa que a questão da relação entre ciência e religião extrapola o próprio âmbito das ideias religiosas e se instala no centro da vida em sociedade, no núcleo da experiência cultural, e que a atualização da investigação proposta por Freud permanece necessária, especialmente em nossos dias, em que esse núcleo 'teológico-político’ vem sofrendo as transformações descritas acima, na direção do fetichismo do objeto. Há também de se considerar a tendência fetichista como tentativa de encantamento de uma sociedade desencantada.

Para Zizek, no momento em que essa figura de Grande Outro entra em eclipse, estamos de volta no ambiente neo-obscurantista de arquétipos masculinos e femininos, do tipo New Age ou junguiano, que caracterizam os nossos dias. Alguns traços característicos: quanto mais a estrutura do sujeito é narcísica, mais culpa será lançada nesse grande Outro (mesmo em eclipse), e mais "queixosa" se torna a cultura - cada indivíduo ou segmento (cada minoria?) reivindicando o acréscimo de gozo a que se julga em pleno direito. Além disso, a derrocada 
da presença do Grande Outro como referência simbólica acaba suscitando o seu aparecimento como Real - a paranóia sendo sua melhor insígnia (as múltiplas conspirações, por exemplo):

Então, o fato de que 'o grande Outro não existe' (como ficção simbólica eficiente) apresenta duas consequências opostas, porém interconectadas: por um lado, a falência da ficção simbólica induz o sujeito a se agarrar mais e mais a simulacros imaginários, aos espetáculos sensuais que nos bombardeiam hoje de todos os lados; por outro, dispara a necessidade de violência no Real do corpo mesmo (cortando e pinçando a carne, ou mesmo inserindo objetos protéticos) (1997).

Não custa imaginar o preço a ser pago pela cultura, pelas artes, com relação a essa demanda por espetáculos de sensualidade (latu sensu) irrefreada.

Ficam as perguntas urgentes e não respondíveis: como sobreviver num mundo onde o desejo vai passando a segundo plano "diante de uma montanha de gozos muito fáceis de satisfazer" ? (Melman, 2003, p. 76) Uma época que torna possível e frequente afirmar e negar as coisas simultaneamente? Devemos ter compromisso com a desmistificação da cultura, ou com a preservação de um significante enigmático?

Perguntamos um tanto espantados sobre que espécie de arte e de cultura será possível gerar doravante, mas não devemos nos esquecer de incluir, em nosso estranhamento, a própria ciência. Que espécie de ciência surge a partir do paradigma da perversão, conjugando possibilidades nunca dantes imaginadas com o decréscimo visível de orientação por um Ideal - ou seja, cada vez mais ondulando com o mercado e suas exigências?

Como evitar o dualismo recorrente do conflito entre fundamentalismos e liberalismos de ordem diversa? Como responder ao problema político central para a cultura, que é a desvinculação entre desamparo versus afeição e reverência pela autoridade versus agressão, estrutura que sustenta a trajetória de cada um, inclusive com relação à religião e à cultura? Ou seja, como "alcançar um estilo de amar mais recíproco e igualitário" um objetivo comum à empreitada psicanalítica e à po- lítica revolucionária, tal como formula Eagleton (1998, p. 209). Em suma: como estabelecer as bases para uma nova política para o supereu, favorecendo aquilo que Safatle denomina de "experiências emancipatórias"? São algumas das questões que permanecem a partir da leitura de $\mathrm{OFu}$ turo de uma Ilusão, envolvendo ciência, religião e cultura.

À guisa de cadência podemos nos referir a uma severa advertência colocada por Freud ao final do capítulo VII:

Desse modo, ou essas massas perigosas terão de ser muito severamente submetidas e com todo cuidado mantidas afastadas de qualquer possibilidade de despertar intelectual, ou então o relacionamento entre civilização e religião terá de sofrer uma revisão fundamental (1974, p. 52-53).

Porém, se não quisermos o peso dessa admoestação, poderemos adotar como cadência o fecho magistral de Emilio Rodrigué para sua biografia de Freud:

Não resta dúvida de que Freud é um parricida contrariado. Ele, que primeiro acreditou na pedofilia dos pais, isto é, na predisposição perversa paterna, a seguir montou a caminhada parricida do homem: trilha que vai do pai da horda a Moisés. Mas Freud, esse 'velho selvagem', não quer ser Moisés, não quer ser parte dessa filiação assassina que caracteriza nosso vale de lágrimas. Ele, como o terrível pai da horda, não quer ser filho de ninguém. Como afirma Marthe Robert, "Ele não é mais judeu que Moisés... Ele não quer ser o filho de ninguém e de nenhum lugar: ele quer ser o filho de sua obra”. Nessa fantasia teogenética, Freud é Deus. O Século da Psicanálise vive nesse planetário. (1995, p. 275).

Recebido para publicação em 28 de julho de 2013 Aceito em 30 de agosto de 2013

\section{REFERÊNCIAS}

BHABHA, Homi. The location of culture. Routledge: Londres, 1994.

DEAN, Tim. Art as Symptom: Zizek and the ethics of psychoanalytic criticism. Diacritics, Baltimore, v. 32 n. 2, Summer, p.20-41, 2002.

EAGLETON, Terry. As ilusões do pós-modernismo. Rio de Janeiro, Zahar, 1998. 
. A ideologia da estética. Rio de Janeiro: Zahar, 1993. FOUCAULT, Michel. As palavras e as coisas. São Paulo, Editora Martins Fontes, 1999.

FREUD, Sigmund. O mal-estar na civilização. São Paulo: Companhia das Letras, 2011. 1974. O mal-etar na civilização. Rio de Janeiro: Imago, . O futuro de uma ilusão. Porto Alegre: P\&PM, 2012. . O futuro de uma ilusão. Rio de Janeiro: Imago, 1974.
MELMAN, Charles. O homem sem gravidade: gozar a qualquer preço. Rio de Janeiro: Companhia de Freud, 2003.

RODRIGUÉ, Emilio. Sigmund Freud: o século da psicanálise 1895-1995. São Paulo: Ed. Escuta, 1995.

SAFATLE, Vladimir. Freud como teórico da modernização bloqueada. A Peste, São Paulo, v.1, n.2 p.355-374, jul./ dez, 2009

. Fetichismo: colonizar o outro. Rio de Janeiro: Civilização Brasileira, 2010.

ZIZEK, Slavoj. The big other doesn't exist. Psychomedia, [S.l.], JEP, n.5, 1997 


\section{THEORY OF CULTURE IN THE PERSPECTIVE OF THE ESSAY "THE FUTURE OF AN ILLUSION" BY FREUD}

\author{
Paulo Costa Lima
}

In this article we seek to make visible the traces of a certain theory of culture present in the discourse of Freud, from the perspective created by the essay The Future of an Illusion. We register a curious parallel between Freud's discourse and that of John Lennon, some decades later. We also present Freud's ideas as parts of a "scientific project" and seek to make visible the multiple relationships established with culture, specially through the analysis of religious ideas, and the context which originated them, infantile helplessness, or human helplessness in general. We will further discuss the nature of this field that takes culture as an opportunity for analysis and interpretation (Cultural Hermeneutics), the notion of 'libideme' as the libidinal counterpart of the ephocal episteme proposed by Foucault, and the horizon of transition from a culture oriented by repression to a culture oriented by perversion all of this coinciding directly over life and art, producing apparently irresolvable questions.

Key Words: Culture and psychoanalysis. Cultural hermeneutics. Composition and culture. Music and psychoanalysis. Religion and culture.

\section{THÉORIE DE LA CULTURE DANS LA PERSPECTIVE CRÉÉE PAR L'OUVRAGE “L'AVENIR D'UNE ILLUSION” DE FREUD}

\author{
Paulo Costa Lima
}

Cet article essaie de reconstruire les indices d'une certaine théorie de la culture présents dans le discours de Freud à partir des perspectives créées par l'ouvrage L'avenir d'une illusion. Nous avons pu établir un curieux parallèle entre le discours de Freud et celui de John Lennon. Nous avons ainsi pu suivre les traces de "la tâche scientifique" qu'il avait entreprise et les multiples relations qui s'établissent avec la culture, en particulier à partir de l'analyse des idées religieuses et de leur origine possible dans le désarroi enfantin, dans le désarroi humain. Nous analysons encore la nature de ce champ qui considère la culture comme l'occasion de faire des analyses et des interprétations, la notion de "libideme" comme l'équivalent plaisant de l'épistémè d'époque proposé par Foucault, et l'horizon de la transition d'une culture orientée par la répression d'une culture axée sur la perversion - tout cela ayant une incidence directe sur la vie et sur l'art et posant des questions urgentes et apparemment impossibles à surmonter.

MOTS-CLÉs: Culture et psychanalyse. Herméneutique culturelle. Composition et culture. Musique et psychanalyse. Religion et culture. 
